\title{
The Role of Composition of Uniform and Highly Dispersed Cobalt Vanadium Iron Spinel Nanocrystals for Oxygen Electrocatalysis
}

Kalapu Chakrapani, ${ }^{a}$ Georg Bendt, ${ }^{a}$ Hamidreza Hajiyani, ${ }^{b}$ Thomas Lunkenbein, ${ }^{c}$ Mark $T$. Greiner, ${ }^{d}$ Liudmyla Masliuk, ${ }^{c}$ Soma Salamon, ${ }^{b}$ Joachim Landers,${ }^{b}$ Robert Schlögl,${ }^{c, d}$ Heiko Wende,${ }^{b}$ Rossitza Pentcheva,${ }^{b}$ Stephan Schulz, ${ }^{a *}$ Malte Behrens ${ }^{a, e} *$

a) Faculty of Chemistry, Inorganic Chemistry, and Center for Nanointegration DuisburgEssen (CENIDE), University of Duisburg-Essen, Universitätsstr. 7, 45114 Essen, Germany.

b) Faculty of Physics and Center for Nanointegration Duisburg-Essen (CENIDE), University of Duisburg-Essen, Lotharstr. 1, 47057 Duisburg, Germany.

c) Fritz-Haber-Institute of the Max-Planck-Society, Department of Inorganic Chemistry, Faradayweg 4-6, 14195 Berlin, Germany.

d) Max-Planck-Institut für Chemische Energiekonversion, Stiftstrasse 34-36, 45470 Mülheim an der Ruhr, Germany.

e) Ertl Center for Electrochemistry and Catalysis, Gwangju Institute of Science (GIST), 123 Cheomdan-gwagiro (Oryang-dong), Buk-gu, Gwangju 500-712, Korea 


\section{ABSTRACT}

Cation substitution in transition metal oxides is an important approach to improve electrocatalysts by the optimization of their composition. Herein, we report on phase-pure spineltype $\mathrm{CoV}_{2-\mathrm{x}} \mathrm{Fe}_{\mathrm{x}} \mathrm{O}_{4}$ nanoparticles with $0 \leq x \leq 2$ as a new class of bi-functional catalysts for the oxygen evolution (OER) and oxygen reduction reactions (ORR). The mixed-metal oxide catalysts exhibit high catalytic activity for both OER and ORR that strongly depends on the V and $\mathrm{Fe}$ content. $\mathrm{CoV}_{2} \mathrm{O}_{4}$ is known to exhibit a high conductivity, while in $\mathrm{CoFe}_{2} \mathrm{O}_{4}$ the cobalt cation distribution is expected to change due to the inversion of the spinel structure. The optimised catalyst, $\mathrm{CoV}_{1.5} \mathrm{Fe}_{0.5} \mathrm{O}_{4}$, shows an overpotential for OER of $\sim 300 \mathrm{mV}$ for $10 \mathrm{~mA} \mathrm{~cm}^{-2}$ with a Tafel slope of $38 \mathrm{mV} \mathrm{dec}{ }^{-1}$ in alkaline electrolyte. DFT $+U+\mathrm{SOC}$ calculations on cation ordering confirm the tendency towards the inverse spinel structure with increasing $\mathrm{Fe}$ concentration in $\mathrm{CoV}_{2-\mathrm{x}} \mathrm{Fe}_{\mathrm{x}} \mathrm{O}_{4}$ that starts to dominate already at low Fe contents. The theoretical results also show that the variation of oxidation states are related to the surface region, where the redox activity was found experimentally to be manifested in the transformation of $\mathrm{V}^{3+} \quad \mathrm{V}^{2+}$. The high catalytic activity, facile synthesis, and low cost of the $\mathrm{CoV}_{2-\mathrm{x}} \mathrm{Fe}_{\mathrm{x}} \mathrm{O}_{4}$ nanoparticles render them very promising for application in bifunctional electrocatalysis.

\section{KEYWORDS}

cobalt vanadate, cobalt ferrite, mixed spinel oxides, composition, oxygen electrocatalysis, DFT 


\section{Introduction}

Design of efficient, affordable and stable electrocatalysts for oxygen electrochemistry is an important goal in the field of energy storage and conversion, i.e. metal-air batteries, fuel cells and water splitting. ${ }^{1-4}$ The sluggish kinetics of both the oxygen evolution reaction (OER) and the oxygen reduction reaction (ORR) due to multiple electron transfer with different reaction intermediates $^{4}$ requires the development of catalysts with high efficiency and long term stability. Precious-metal electrocatalysts such as Pt and its alloys are known to be efficient catalysts for ORR but show only moderate activity for OER, whereas $\mathrm{IrO}_{2}$ and $\mathrm{RuO}_{2}$ are known to be good catalyst for OER but less active for ORR., ${ }^{5,6}$ Therefore, highly active and low-cost bifunctional catalysts still have to be developed to replace these noble metals. Among various material candidates, extensive efforts have been taken to develop mixed first-row transition metal oxides (perovskites and spinels) and hydroxides (LDH, layered double hydroxides) due to their earth abundance and promising catalytic characteristics. ${ }^{7-20}$

Active sites in electrocatalysis on these types of oxides and hydroxides are generally related to the generation of defects or vacancies as well as to the tuning of the chemical composition..$^{8,14,20}$ Zhang et al. recently demonstrated that the electronic configuration and adsorption energies of ternary mixed metal oxides significantly depends on their chemical composition. Therefore, their catalytic activity can likely be tuned by carefully adjusting the metal composition. ${ }^{20}$ Furthermore, the electronic configuration of octahedrally coordinated Co cations with $\mathrm{e}_{\mathrm{g}}$ occupancy neighboring a metal center with covalent metal-oxygen bonds was shown to exhibit high OER and ORR activities in perovskite-type oxides..$^{21,22}$ In the case of hydroxides, incorporation of Fe 
dramatically improves the OER activity of both $\mathrm{Ni}$ - and Co-based LDH catalysts. It was proposed, that $\mathrm{Fe}$ was the active site while the Ni- and Co-LDH framework acted as conductive support. ${ }^{17}$ However, in contrast to Ni-based LDHs, Co-based LDHs exhibit relatively high intrinsic activity even without $\mathrm{Fe}$, which suggests a synergistic cooperation between $\mathrm{Co}$ and $\mathrm{Fe}$ sites. ${ }^{17}$ Interestingly, it was reported that the substitution of iron by vanadium leads to another special synergistic effect on Ni-LDH due to a higher electric conductivity. ${ }^{13}$ Very recently, hollow Fe-V composite materials without any additional $\mathrm{Co}$ or $\mathrm{Ni}$ have been reported as efficient electrocatalysts for water oxidation..$^{23}$

Spinel-type oxides of the general type $\mathrm{AB}_{2} \mathrm{O}_{4}$ have attracted a great deal of research interest in this context. The spinel structure is a cubic closed packed array of $\mathrm{O}^{2-}$ ions, with $\mathrm{A}^{2+}$ and $\mathrm{B}^{3+}$ metal cations occupying the tetrahedral $\left(\mathrm{T}_{\mathrm{d}}\right)$ and octahedral $\left(\mathrm{O}_{\mathrm{h}}\right)$ voids. ${ }^{7,24-27}$ An important parameter proposed to be relevant for the ORR activity of spinel-type oxides is the inversion parameter of the spinel structure, which determines the distribution of the cations between tetrahedral and octahedral sites. ${ }^{25}$ We have recently studied the OER activity of $\mathrm{Co}_{1-\mathrm{x}} \mathrm{Ni}_{\mathrm{x}} \mathrm{Fe}_{2} \mathrm{O}_{4}$ spinel-type nanoparticles and found the highest activity in mixed ternary catalysts. ${ }^{28}$ The metal composition was found to have a more distinct impact on the catalytic performance than the particle size or structural inversion in this system. However, the cation distribution did not change much upon $\mathrm{Co}, \mathrm{Ni}$ substitution and remained largely inverse in the ternary ferrites. A more pronounced effect is expected upon iron incorporation into cobalt vanadate $\left(\mathrm{CoV}_{2} \mathrm{O}_{4}\right)$, which is expected to change from a normal to an inverse spinel $\mathrm{CoFe}_{2} \mathrm{O}_{4}$. Among the many possible spinel-type compositions, cobalt vanadate is also interesting, because it exhibits near metallic electric conductivity providing a unique situation unlike the insulating $\mathrm{AV}_{2} \mathrm{O}_{4}(\mathrm{~A}=\mathrm{Mn}$, $\mathrm{Fe}$ ) due to close proximity of itineracy between $\mathrm{e}^{4} \mathrm{t}_{2}{ }^{3}$ orbital of tetrahedrally coordinated $\mathrm{Co}^{2+}$ 
with $\mathrm{t}_{2 \mathrm{~g}}{ }^{2}$ of $\mathrm{V}^{3+}$ ions. ${ }^{29} \mathrm{CoV}_{2} \mathrm{O}_{4}$ has complicated physical properties attributed to this spin exchange interactions of $\mathrm{V}^{3+}$ and $\mathrm{Co}^{2+}$ on corner sharing tetrahedral sites. ${ }^{29,30}$ Given the intrinsic activity of cobalt oxides in oxygen electrochemistry and the above-mentioned electrical conductivity of $\mathrm{CoV}_{2} \mathrm{O}_{4}$, it appears to be a highly attractive material for an oxygen electrocatalyst as a similar synergistic effect as observed for the LDHs might be expected.

Nanostructured cobalt vanadate $\mathrm{Co}_{3} \mathrm{~V}_{2} \mathrm{O}_{8}$ exhibits high performance for lithium storage, as super capacitors and oxygen evolution reaction, ${ }^{12,31-33}$ but there are only very few reports on the oxygen electrocatalysis of these materials. We herein present a systematic study of the metal composition in uniform and phase-pure $\mathrm{CoV}_{2-\mathrm{x}} \mathrm{Fe}_{\mathrm{x}} \mathrm{O}_{4}$ nanoparticles $(\mathrm{x}=0$, 0.5, 1, 1.5, 2), which are explored as electrocatalyst for OER and ORR. The phase-pure nature of these catalysts renders them suitable materials for fundamental insights by relating structural and surface properties with electrocatalytic performance.

\section{Results and Discussion}

\subsection{Synthesis and Characterization of Spinel-type Vanadates}

$\mathrm{CoV}_{2-\mathrm{x}} \mathrm{Fe}_{\mathrm{x}} \mathrm{O}_{4}$ nanoparticles with $x$ varying between 0 and 2 were prepared by thermal decomposition of the corresponding metal acetylacetonate complexes $\mathrm{M}(\mathrm{acac})_{3}(\mathrm{M}=\mathrm{Fe}, \mathrm{V})$ and $\mathrm{Co}(\mathrm{acac})_{2}$ in the desired molar ratio in oleylamine at $250{ }^{\circ} \mathrm{C}$. The resulting nanoparticles are crystalline as shown by powder X-ray diffraction (Figure 1A). XRD patterns show broad Bragg reflections at 2 values of $30.2^{\circ}, 35.6^{\circ}, 43.4^{\circ}, 57.2^{\circ}, 62.6^{\circ}$ corresponding to the $(220),(311)$ (400), (511) and (440) lattice planes of cubic spinel-type phase $\left(\mathrm{CoFe}_{2} \mathrm{O}_{4}\right.$, PDF 22-1086, with $a=$

$8.3919 \AA$ ). The broadening of the peaks is attributed to the nanoscale crystalline domains and samples with high vanadium content show broader peaks, indicative of smaller crystallites. The 
formation of other crystalline phases including elemental metals or other non-spinel-type oxides (e.g., hematite or $\left.\mathrm{Co}_{3} \mathrm{~V}_{2} \mathrm{O}_{8}\right)$ is not observed. It is noted that the lattice parameter of $\mathrm{CoV}_{2} \mathrm{O}_{4}(x=$ 0 ) is $a=8.407 \AA$ and thus very similar to that of $\mathrm{CoFe}_{2} \mathrm{O}_{4}$, leading to only small variations in the peak positions with variation of $x .^{34}$
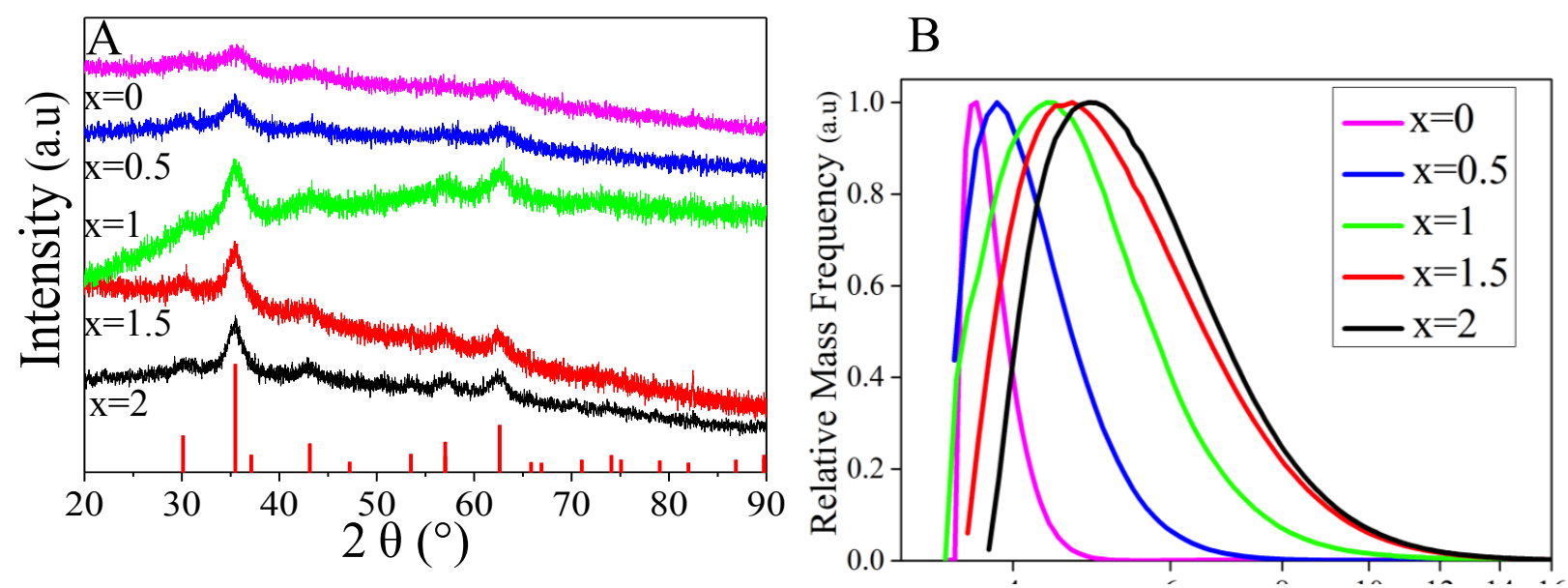

Figure 1. A) $\mathrm{X}$-ray diffraction patterns and $\mathrm{B}$ ) size distributions as determined by disc centrifugation of different $\mathrm{CoV}_{2-\mathrm{x}} \mathrm{Fe}_{\mathrm{x}} \mathrm{O}_{4}$ nanoparticles. The red bar patterns refers to $\mathrm{CoFe}_{2} \mathrm{O}_{4}$ (PDF 22-1086). The reference pattern of $\mathrm{CoV}_{2} \mathrm{O}_{4}$ is nearly indistinguishable from that of $\mathrm{CoFe}_{2} \mathrm{O}_{4}$.

The size distribution of the $\mathrm{CoV}_{2-\mathrm{x}} \mathrm{Fe}_{\mathrm{x}} \mathrm{O}_{4}$ nanoparticles was analyzed using disc centrifuge measurements as shown in Figure 1B. In accordance with the peak widths, the hydrodynamic radii of the $\mathrm{CoV}_{2-\mathrm{x}} \mathrm{Fe}_{\mathrm{x}} \mathrm{O}_{4}$ nanoparticle samples continuously decrease with increasing vanadium content from an average value of $4.9 \mathrm{~nm}$ for $\mathrm{CoFe}_{2} \mathrm{O}_{4}$ to $3.6 \mathrm{~nm}$ for $\mathrm{CoV}_{2} \mathrm{O}_{4}$. The particle size distribution is relatively narrow showing only very few particles with a size larger than $10 \mathrm{~nm}$. The elemental composition of the samples as determined by EDSspectroscopy (Table S1) shows ratios very close to the expected nominal compositions of $\mathrm{CoV}_{2-\mathrm{x}} \mathrm{Fe}_{\mathrm{x}} \mathrm{O}_{4}(x=0,0.5,1.0,1.5,2.0)$. 
$\mathrm{CoV}_{2-\mathrm{x}} \mathrm{Fe}_{\mathrm{x}} \mathrm{O}_{4}$ nanoparticles with $x=0,1$, and 2 were also investigated by annular dark-field scanning transmission electron microscopy (ADF-STEM, Figure 2 and Figure S1).
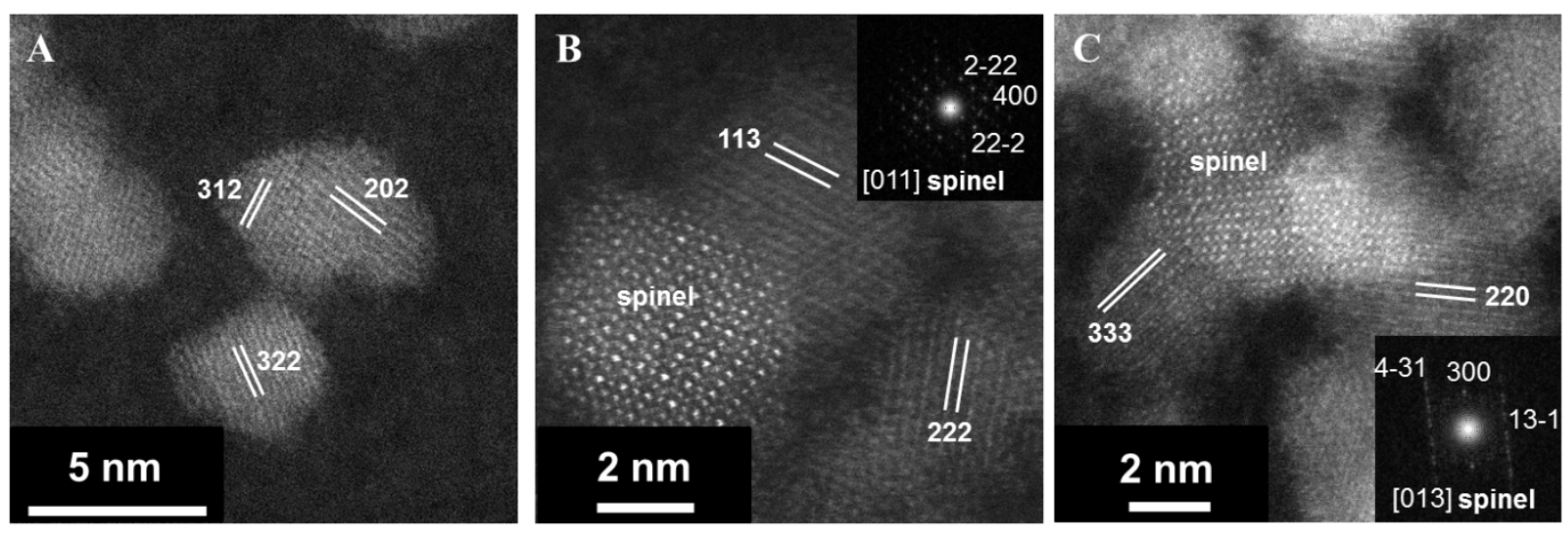

Figure 2: High resolution images of spinel-type $\mathrm{CoV}_{2-\mathrm{x}} \mathrm{Fe}_{\mathrm{x}} \mathrm{O}_{4}(\mathrm{x}=0$-2) nanoparticles: (A) $\mathrm{CoFe}_{2} \mathrm{O}_{4}$, (B) $\mathrm{CoFeVO}_{4}$, and (C) $\mathrm{CoV}_{2} \mathrm{O}_{4}$. The inset in (B) and (C) denote Fast Fourier transformation of the nanoparticles labeled with "spinel".

High resolution ADF-STEM images (Figure 2) corroborate the formation of crystalline spinel nanoparticles. As opposed to the pure cobalt ferrite nanoparticles,${ }^{28}$ substitution of iron cations by vanadium seems to result in a partial agglomeration of spinel- nanoparticles (Figure S1). The individual particle sizes of $\mathrm{CoFeVO}_{4}$ and $\mathrm{CoV}_{2} \mathrm{O}_{4}$ range between 4.3 and $8.3 \mathrm{~nm}$ in good agreement with the disc centrifuge measurements (Figure 1B).

The element-specific valence states near the surface of $\mathrm{CoV}_{2-\mathrm{x}} \mathrm{Fe}_{\mathrm{x}} \mathrm{O}_{4}$ spinels were determined using X-ray photoelectron spectroscopy (XPS). Figure 3 shows the V2p, Co2p and Fe2p corelevel XP spectra of two ternary $\mathrm{CoV}_{2-\mathrm{x}} \mathrm{Fe}_{\mathrm{x}} \mathrm{O}_{4}$ samples with varying compositions $(x=0.5,1.5)$. The observed binding energies (B.E.) which are in good agreement with spinel-type vanadates, supporting the formation of mixed oxides. ${ }^{23,28}$ The deconvoluted $\mathrm{V} 2 \mathrm{p}$ spectra of $\mathrm{CoV}_{2-\mathrm{x}} \mathrm{Fe}_{\mathrm{x}} \mathrm{O}_{4}$ in Figure $3 \mathrm{~A}$ reveal that the vanadium species are primarily $\mathrm{V}^{3+}$ (binding energy of ca. $516.5 \mathrm{eV}$ ) 
with a minor contribution from $\mathrm{V}^{2+}$ (binding energy of ca. $514.7 \mathrm{eV}$ ). The proportion of $\mathrm{V}^{2+}$ to $\mathrm{V}^{3+}$ is higher in the $x=0.5$ composition. Note that the peak at $521.5 \mathrm{eV}$ is a satellite from the
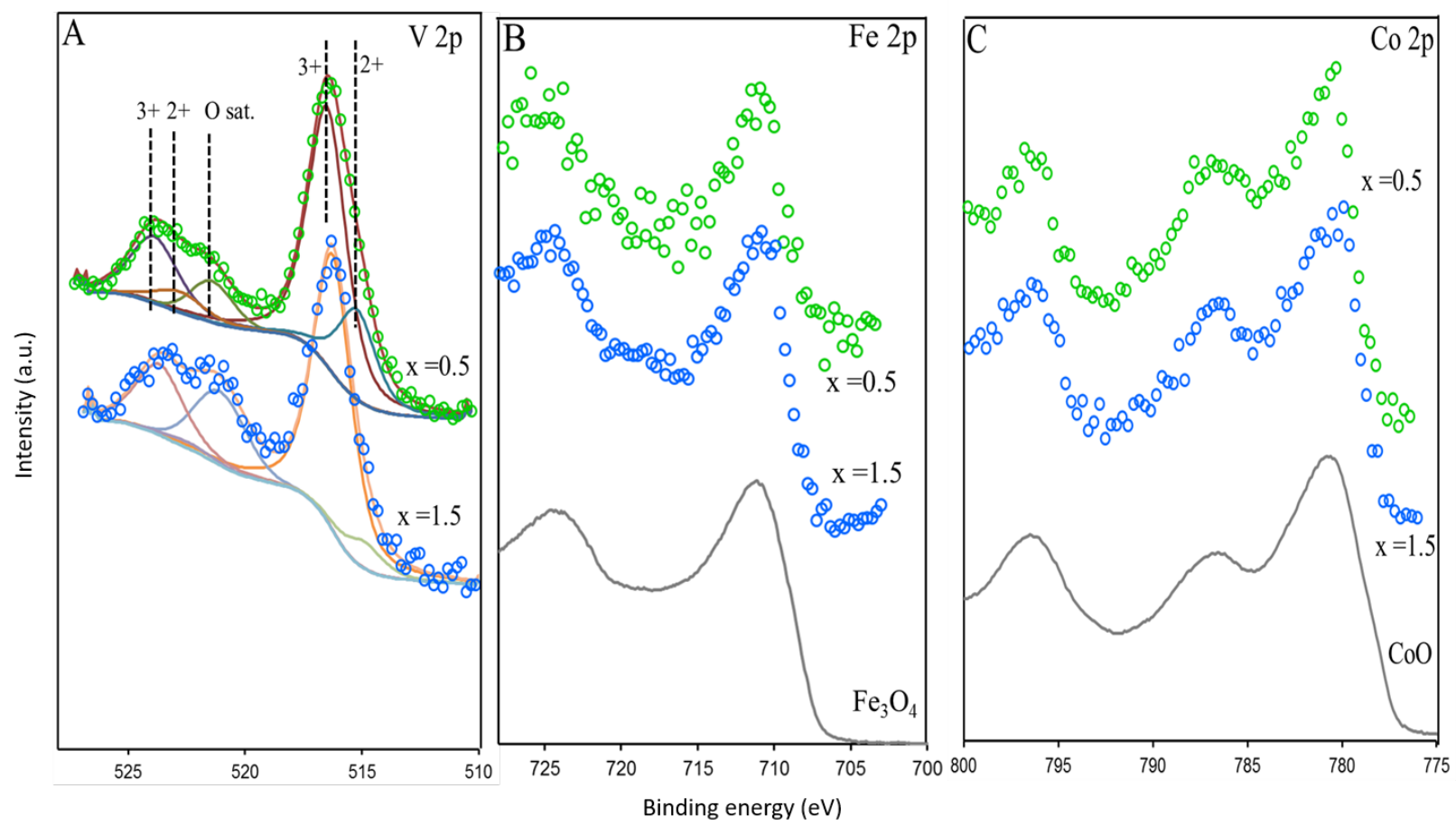

Figure 3. XPS spectra A) V 2p; B) Fe2p; and C) Co2p regions of $\mathrm{CoV}_{2-\mathrm{x}} \mathrm{Fe}_{\mathrm{x}} \mathrm{O}_{4}$. The energy scale was calibrated using the $\mathrm{C} 1 \mathrm{~s}$ peak of adventitious carbon at $284.5 \mathrm{eV}$. The grey spectra in $\mathrm{B}$ and $\mathrm{C}$ are reference spectra of $\mathrm{Fe}_{3} \mathrm{O}_{4}$ and $\mathrm{CoO}$, respectively.

$\mathrm{O}$ 1s spectrum, due to the non-monochromated X-rays used to measure the spectrum. ${ }^{23,35,36}$ The partial substitution of vanadium by iron results is believed to be the origin of the $\mathrm{V}^{2+}$ species. The existence of the $\mathrm{V}^{2+}$ oxidation state was previously observed in magmatic rocks stabilized by spinel structure and also in iron vanadium spinels..$^{37,38}$

The Fe2p spectra of $\mathrm{CoFe}_{2-\mathrm{x}} \mathrm{V}_{\mathrm{x}} \mathrm{O}_{4}$ are shown in Figure 3B. Due to the highly complex peak shape of $\mathrm{Fe} 2 \mathrm{p}$ in oxides, peak fitting was not used to deconvolute the spectra. ${ }^{39,40}$ Instead they are 
compared with iron oxide reference spectra. From Figure 3B, one can see that the peak shape and binding energy $(\mathrm{BE}=710.9 \mathrm{eV})$ are similar to that of $\mathrm{Fe}_{3} \mathrm{O}_{4}$, suggesting that the $\mathrm{Fe}$ oxidation state in $\mathrm{CoFe}_{2-\mathrm{x}} \mathrm{V}_{\mathrm{x}} \mathrm{O}_{4}$ is a mixture of $\mathrm{Fe}^{2+}$ and $\mathrm{Fe}^{3+}$. No differences between the $x=0.5$ and 1.5 spectra can be seen in Figure 3B, likely due to the low signal intensity and that such differences are expected to be very subtle. The Co2 $\mathrm{p}_{3 / 2}$ spectra are shown in Figure 3C. Again, due to the complex peak shape, the spectra were not deconvoluted, but rather compared to reference spectra. The $\mathrm{CoO}$ spectrum in Figure $3 \mathrm{C}$ shows a very similar qualitative line shape and chemical shift $(\mathrm{BE}=779.5 \mathrm{eV})$ as the $\mathrm{Co} 2 \mathrm{p}$ spectra of the $\mathrm{CoFe}_{2-\mathrm{x}} \mathrm{V}_{\mathrm{x}} \mathrm{O}_{4}$ spinels. ${ }^{41-43}$ This observation suggests that the spinels consist primarily of $\mathrm{Co}^{2+}$ species. Again, due to the low signal intensity, subtle differences among the two spectra cannot be discerned.

\subsection{Composition dependent oxygen electrocatalysis of $\mathrm{CoV}_{2-\mathrm{x}} \mathrm{Fe}_{\mathrm{x}} \mathrm{O}_{4}$}

The influence of the chemical composition of $\mathrm{CoV}_{2-\mathrm{x}} \mathrm{Fe}_{\mathrm{x}} \mathrm{O}_{4}$ nanoparticles was evaluated for both oxygen evolution (OER) and oxygen reduction reactions (ORR) in $1 \mathrm{M} \mathrm{KOH}$ solution by using a three electrode system at a scan rate of $5 \mathrm{mV} \mathrm{sec}{ }^{-1}$. The particular interest was to identify the distinctive role of the $\mathrm{V}^{3+}$ to $\mathrm{Fe}^{3+}$ ratio on the resulting electrocatalytic activity of $\mathrm{CoV}_{2-\mathrm{x}} \mathrm{Fe}_{\mathrm{x}} \mathrm{O}_{4}$ nanoparticles. The OER performance strongly depends on $x$ and $\mathrm{CoV}_{2} \mathrm{O}_{4}$ showed a higher electrocatalytic OER activity compared to pure $\mathrm{CoFe}_{2} \mathrm{O}_{4}$, most likely resulting from the metalliclike conductivity of $\mathrm{CoV}_{2} \mathrm{O}_{4}$. However, these binary oxides $(x=0,2.0)$ show the lowest catalytic activity compared to all ternary catalysts with mixed spinel-type oxides $\mathrm{CoV}_{2-\mathrm{x}} \mathrm{Fe}_{\mathrm{x}} \mathrm{O}_{4}(x=0.5$, 1.0, 1.5; Figure 4A and Figure S2). It appears that the co-existence of $\mathrm{V}^{3+}$ and $\mathrm{Fe}^{3+}$ ions in the spinel-type lattice plays an essential role for the catalytic activity. The overpotential required to deliver a $10 \mathrm{~mA} \mathrm{~cm}{ }^{-2}$ current density, that is estimated to be a suitable figure of merit for a solar fuel production, was used to evaluate the OER activity. ${ }^{6,22}$ The best composition for the OER 
activity was found in $\mathrm{CoV}_{1.5} \mathrm{Fe}_{0.5} \mathrm{O}_{4}(x=0.5)$ with an overpotential of $\sim 0.3 \mathrm{~V}$, which represents the smallest value within the materials investigated $\left(\mathrm{CoV}_{2} \mathrm{O}_{4} \sim 0.35 \mathrm{~V}, \mathrm{CoFe}_{2} \mathrm{O}_{4} \sim 0.36 \mathrm{~V}\right.$, $\left.\mathrm{CoV}_{0.5} \mathrm{Fe}_{1.5} \mathrm{O}_{4} \sim 0.33 \mathrm{~V}, \mathrm{CoVFeO}_{4} \sim 0.31 \mathrm{~V}\right)$. To better locate the activity maximum on the composition scale, an additional sample with $x=0.25$ was synthesized and its overpotential was found to be $0.31 \mathrm{~V}$ (Figure 4C) fitting perfectly to the trend and showing that the promotional effect was indeed strongest for $x=0.5$.
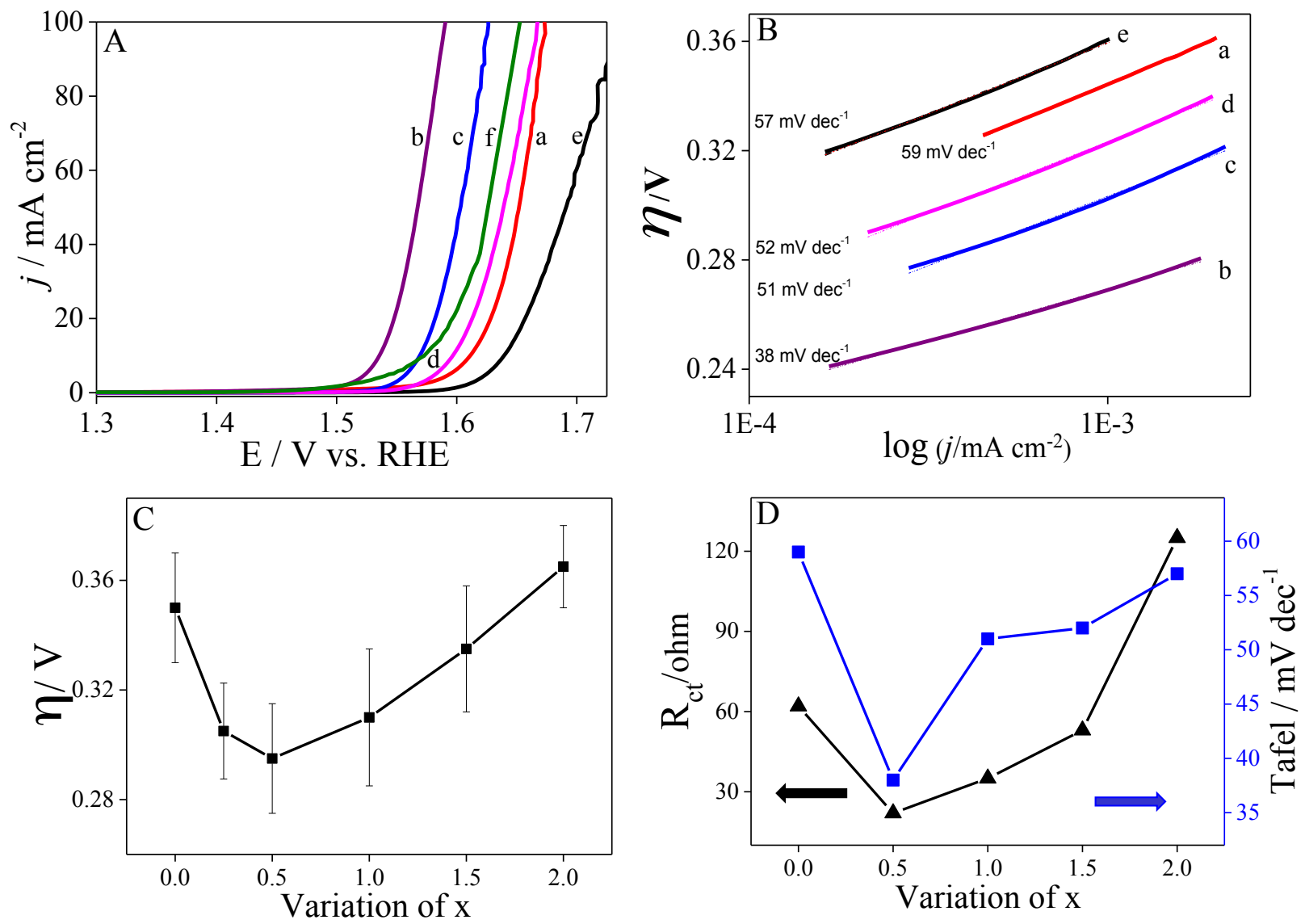

Figure 4. OER activities of different $\mathrm{CoV}_{2-\mathrm{x}} \mathrm{Fe}_{\mathrm{x}} \mathrm{O}_{4}$ compositions in $1 \mathrm{M} \mathrm{KOH}$ solution at rotation speed of $1600 \mathrm{rpm}$ with scan rate of $5 \mathrm{mV} \mathrm{s}^{-1}$. A) OER activity and B) Tafel slope derived from voltammograms of a) $x=0$; b) $x=0.5$; c) $x=1.0$; d) $x=1.5$; e) $x=2.0$ and f) commercial $\mathrm{IrO}_{2}$. C) Overpotentials required at $\mathrm{j}=10 \mathrm{~mA} \mathrm{~cm}$ of $\mathrm{CoV}_{2-\mathrm{x}} \mathrm{Fe}_{\mathrm{x}} \mathrm{O}_{4}$ (error bars represent the scattering between several electrode preparations and measurements); D) Charge transfer resistance and Tafel slope of $\mathrm{CoV}_{2-\mathrm{x}} \mathrm{Fe}_{\mathrm{x}} \mathrm{O}_{4}$. 
The improved catalytic activity of the V-and Fe-containing mixed spinel-type oxides and their trend is not only observed in the overpotentials, but also in the Tafel analysis. Tafel slopes are an important parameter, which offer insights into the OER reaction kinetics were measured by fitting the polarization data to the Tafel equation $(\eta=a+b \log j), \eta$ is the over potential, $b$ is the Tafel slope, and $j$ is the current density). A linear dependency of $\eta$ vs. $\log (\mathrm{j})$ with different slopes was observed for all catalysts. $\mathrm{CoV}_{1.5} \mathrm{Fe}_{0.5} \mathrm{O}_{4}$ exhibits a lower Tafel slope of $38 \mathrm{mV} \mathrm{dec}{ }^{-1}$ as compared to pure $\mathrm{CoV}_{2} \mathrm{O}_{4}\left(59 \mathrm{mV} \mathrm{dec}{ }^{-1}\right), \mathrm{CoFe}_{2} \mathrm{O}_{4}\left(58 \mathrm{mV} \mathrm{dec}^{-1}\right)$ and $\mathrm{CoFeVO}_{4}\left(51 \mathrm{mV} \mathrm{dec}^{-1}\right)$ as shown in Figure 4B and 4D. The lower Tafel slope of $\mathrm{CoV}_{1.5} \mathrm{Fe}_{0.5} \mathrm{O}_{4}$ indicates a favorable electron transport, resulting in an increased OER activity. Furthermore, we measured the linear slope of the capacitive current with variation of scan rate (Figure S3) equivalent to twice of the double-layer capacitance $\left(\mathrm{C}_{\mathrm{d} 1}\right)$ of the catalysts using cyclic voltammetry. ${ }^{13,44,45} \mathrm{High}$ active surface area (ECSA) is the prerequisite for an efficient electrocatalyst. The slope for the charging current of $\mathrm{CoV}_{1.5} \mathrm{Fe}_{0.5} \mathrm{O}_{4}$ is significantly larger than that of the other catalysts $\left(\mathrm{CoV}_{2} \mathrm{O}_{4}, \mathrm{CoFe}_{2} \mathrm{O}_{4}\right)$, indicating a large number of exposed surface sites to be active in the OER on this catalyst. These results also show that the high catalytic activity of $\mathrm{CoV}_{1.5} \mathrm{Fe}_{0.5} \mathrm{O}_{4}$ can be attributed to the enhanced anion exchangeability between the electrolyte and electrode resulting in the increased number of catalytic active sites. To examine the electrode kinetics, electrical impedance spectroscopy (EIS) was used to characterize the interfacial electrode kinetics and resistance of the material. The charge transfer resistance $\mathrm{R}_{\mathrm{ct}}$ was obtained by fitting of Nyquist plot data using Randles circuit, recorded at an overpotential of $0.35 \mathrm{~V}$. The Nyquist plot shows semi-circle in high frequency range mainly associated with charge transfer resistance and the diameter of the semicircles decrease with substituting $\mathrm{Fe}^{3+}$ by $\mathrm{V}^{3+}$ ions in $\mathrm{CoV}_{2-\mathrm{x}} \mathrm{Fe}_{\mathrm{x}} \mathrm{O}_{4}$ (Figure S4). The EIS data (Figure 4D) reveal a significantly lower charge-transfer resistance $\left(\mathrm{R}_{\mathrm{ct}} \sim 25 \mathrm{ohm}\right)$ for 
$\mathrm{CoV}_{1.5} \mathrm{Fe}_{0.5} \mathrm{O}_{4}$ as compared to pure $\mathrm{CoV}_{2} \mathrm{O}_{4}(62 \mathrm{ohm}), \mathrm{CoFe}_{2} \mathrm{O}_{4}(125 \mathrm{ohm})$ and $\mathrm{CoFeVO}_{4}(35$ ohm), respectively. The superior charge transport kinetics of $\mathrm{CoV}_{1.5} \mathrm{Fe}_{0.5} \mathrm{O}_{4}$ results in an effective charge transfer, which is in good agreement with the low Tafel slope and low overpotential values.

The improved OER activity thus can be related to synergetic effects of V, Fe and Co sites in the spinel-type mixed metal oxides and can rationalized by the following aspects. One factor that influences the catalytic activity may be attributed to the easier valance change of the accessible $\mathrm{Co}^{2+/ 3+}$ sites. The highest abundance of $\mathrm{V}^{2+}$ of the most active pre-catalyst might be an indication for an internal redox couple $\mathrm{Co}^{2+}+\mathrm{V}^{3+} \mathrm{Co}^{3+}+\mathrm{V}^{2+}$ in the presence of low amounts of $\mathrm{Fe}^{3+}$. It is noted that the $\mathrm{V}^{2+}$ abundance was lowered again for the newly prepared iron poorer sample $\mathrm{x}=$ 0.25 following the trend in reactivity (Figure S5). Additionally, the electrical conductivity of Vcontaining ferrite spinels, which generally related to an electron hopping process involving the redox-active $\mathrm{Fe}^{3+} / \mathrm{Fe}^{2+}$ couple, is higher since $\mathrm{CoV}_{2} \mathrm{O}_{4}$ show metallic behavior due to the localized itinerant electronic transition of $\mathrm{Co}$ and $\mathrm{V}$. This can lead to a lower charge transfer resistance with improved OER activity as observed by the low charge transfer resistance of all $\mathrm{V}$ containing samples and in particular of $\mathrm{CoV}_{1.5} \mathrm{Fe}_{0.5} \mathrm{O}_{4}$. Furthermore, the observed OER activity may be related to the change in coordination environment of cobalt cations from tetrahedral to octahedral environment at the catalyst surface, ${ }^{27}$ introduced by the structural inversion as $\mathrm{V}^{3+}$ is gradually replaced by $\mathrm{Fe}^{3+}$.

Furthermore, the $\mathrm{CoV}_{2-\mathrm{x}} \mathrm{Fe}_{\mathrm{x}} \mathrm{O}_{4}$ nanoparticles were also investigated for the oxygen reduction reaction (ORR). The measurements were done in $\mathrm{O}_{2}$ saturated $1 \mathrm{M} \mathrm{KOH}$ solution. Figure $5 \mathrm{~A}$ and Figure S6 show the LSV, which shows no obvious peak in $\mathrm{N}_{2}$-saturated $1 \mathrm{M} \mathrm{KOH}$ solution, whereas a pronounced cathodic peak is clearly observed in $\mathrm{O}_{2}$-saturated solution assigned to the 
reduction of oxygen. Notably, $\mathrm{CoV}_{1.5} \mathrm{Fe}_{0.5} \mathrm{O}_{4}$ exhibits a cathodic peak at $0.664 \mathrm{~V}$ vs. RHE, which is more positive than those of the pure $\mathrm{CoV}_{2} \mathrm{O}_{4}(0.595 \mathrm{~V}), \mathrm{CoFe}_{2} \mathrm{O}_{4}(0.573 \mathrm{~V})$ and $\mathrm{CoFeVO}_{4}$ $(0.615 \mathrm{~V})$ catalysts. Thus the trend is similar to the OER studies. However, the activity of the spinel-type nanoparticles is lower compared to previously reported spinels, in which the catalysts
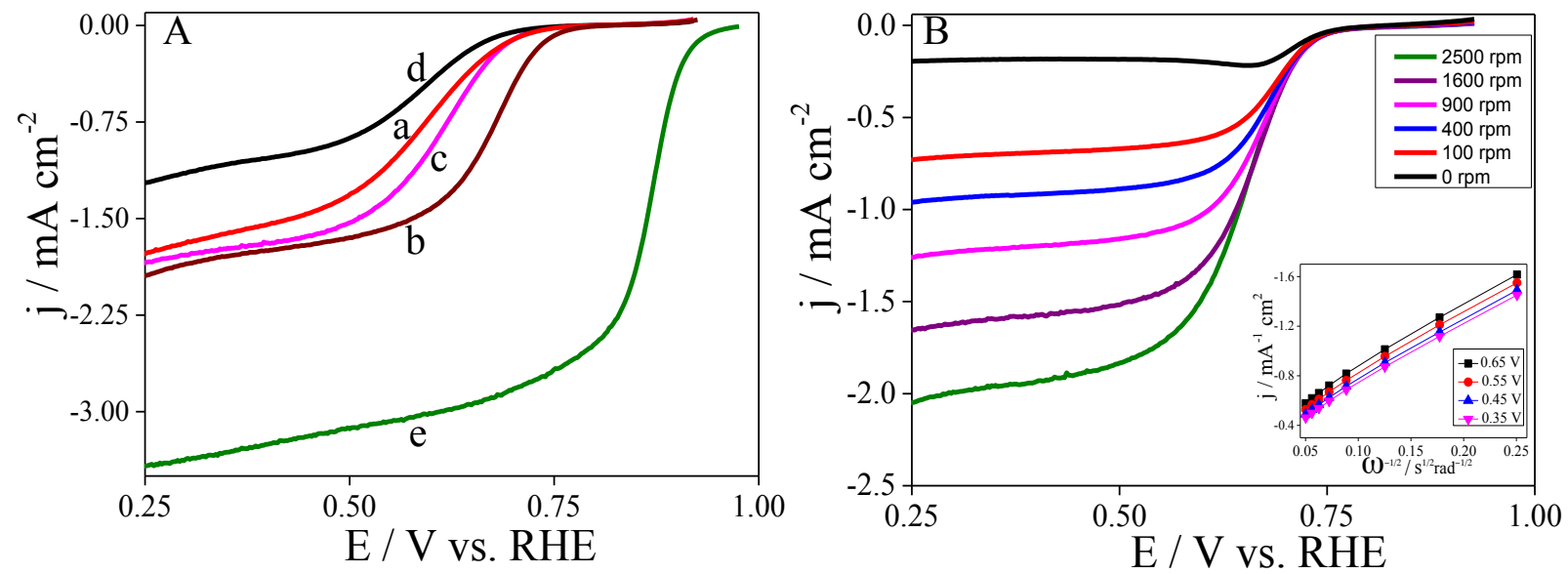

Figure 5. A) ORR activity of a) $x=0$; b) $x=0.5$; c) $x=1$; d) $x=2$ and e) commercial $\mathrm{Pt} / \mathrm{C}$ in $\mathrm{O}_{2}$ saturated $1 \mathrm{M} \mathrm{KOH}$ solution at rotation speed of $1600 \mathrm{rpm}$ with $5 \mathrm{mVs}^{-1}$. B) Effect of different rotation rates of $\mathrm{CoV}_{1.5} \mathrm{Fe}_{0.5} \mathrm{O}_{4}$ for ORR activity. Inset shows the $\mathrm{K}-\mathrm{L}$ plots at different potentials.

were mostly anchored on conductive substrates such as graphene or carbon nanotubes. ${ }^{46}$ Rotating disc electrode (RDE) measurements were carried out to investigate the activity and kinetics for ORR in linear potential scan mode. The reduction currents increase as a function of rotation rate $^{47}$ due to the availability of large reactant flux near the electrode surface, as shown in Figure 5B. The kinetic parameters are calculated by analyzing the RDE data based on the KouteckyLevich equation, inverse of current density $\left(j^{-1}\right)$ as a function of the inverse of square root of rotating speed $\left(\omega^{-1 / 2}\right)$ at different potentials from 0.35 to $0.65 \mathrm{~V}$ (Figure $5 \mathrm{~B}$ ). The corresponding Koutecky-Levich plots are linear at different potentials and the number of electrons determined 
at different potentials is calculated to be in the range 3.5-3.7 for the potential range measured, in reasonable agreement with the ORR being a four-electron process. The ORR activity depends on the number of efficient active sites for molecular adsorption of oxygen and surface defects present on the catalyst surface. ${ }^{48,49}$ Recently, it was proposed that the activity of ferrites towards ORR is promoted by inversion on its spinel structure from the normal to the inverse leading to acceleration of $\mathrm{O}-\mathrm{O}$ cleavage ${ }^{24}$. Hence, the improved activity of $\mathrm{CoV}_{1.5} \mathrm{Fe}_{0.5} \mathrm{O}_{4}$ compared to the other compositions again can be assumed to be partially due to the higher structural inversion with more available octahedral cobalt sites in the pre-catalyst.

\subsection{Computational results}

As outlined above, an important parameter that may influence the electrochemical performance is the cation ordering in the spinel structure. Density functional theory (DFT) by taking into account of spin-orbit interaction (SOC) were used to resolve the most stable cation ordering in $\mathrm{CoV}_{2-\mathrm{x}} \mathrm{Fe}_{\mathrm{x}} \mathrm{O}_{4}$ (for complete details, see experimental section). ${ }^{50,51}$ Figure 6 shows formation energies and the most stable configurations of $\mathrm{CoV}_{2-\mathrm{x}} \mathrm{Fe}_{\mathrm{x}} \mathrm{O}_{4}$ for three different inversion parameters $\lambda$, namely $\lambda=0.0$ corresponding to a normal spinel (all $\mathrm{A}^{2+}$ on $\mathrm{T}_{\mathrm{d}}$ ), $\lambda=1.0$ corresponding to an inverse spinel (all $\mathrm{A}^{2+}$ on $\mathrm{O}_{\mathrm{h}}$ ), and $\lambda=0.5$ representing a situation, in which half of the $\mathrm{A}^{2+}$ cations reside on each the $\mathrm{O}_{h}$ and $\mathrm{T}_{\mathrm{d}}$ sites. The magnetic moments are shown in Figure S7-S8 andthe formation energies without SOC in Figure S9. Spins aligned along the hard [001]-axis and spins rotated along the easy [010]- and [100]-axes are denoted by black and yellow arrows, respectively. The stable configuration for $\mathrm{CoV}_{2} \mathrm{O}_{4}$ is the normal spinel in agreement with experimental reports. ${ }^{52}$ 
The corresponding magnetic moments of $\mathrm{V}^{3+}$ are $2.6 \mu_{\mathrm{B}}$ and $0.5 \mu_{\mathrm{B}}$ along the hard and easy axes while the magnetic moments of $\mathrm{Co}^{2+}$ ions at tetrahedral sites are aligned along the hard axis. In $\mathrm{CoV}_{1.5} \mathrm{Fe}_{0.5} \mathrm{O}_{4}$, the half inverse spinel $(\lambda=0.5)$ appears at the convex hull where the $\mathrm{T}_{\mathrm{d}}$ sites are occupied exclusively by $\mathrm{Fe}^{3+}$ and $\mathrm{Co}^{2+}$. The normal spinel phase is just $10 \mathrm{meV} /$ atom above the convex hull and this energetic similarity of the normal and the half inverse spinel may be speculated to be related to the special electronic situation at the surface. The most active catalyst

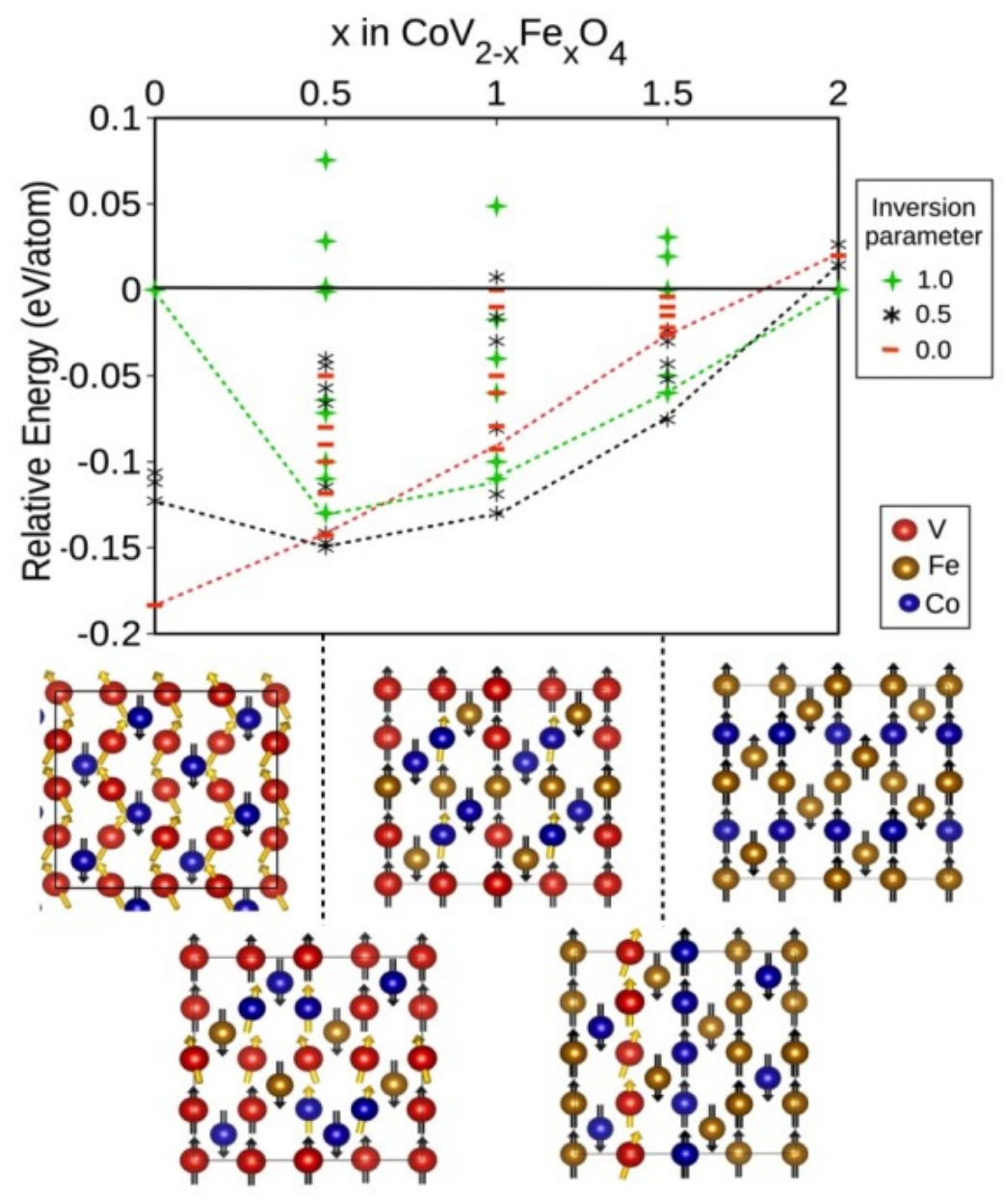

Figure 6. Relative formation energies of different $\mathrm{Co}-\mathrm{Fe}-\mathrm{V}$ ordering in $\mathrm{CoV}_{2-\mathrm{x}} \mathrm{Fe}_{\mathrm{x}} \mathrm{O}_{4}$ for inversion parameters $\lambda=0.0,0.5,1.0$ within DFT/GGA+U, taking into account SOC. Crystal structures of the most stable configurations and magnetic orders denoted by arrows are also shown for each concentration $x$. (The sizes of arrows for the different chemical species are normalized for better visibility, the actual sizes of magnetic moments are given in SI, Figure S7). 
with $x=0.5$ is found at the point of interception of the black and red curves in Figure 6 . At the same composition of $x=0.5$, the half and fully inverted structures show their energy minima due to a strong stabilization of the inverted structures with increasing Fe content from 0 to 0.5 . As the normal structure is destabilized at the same time, the inverted structures become energetically favorable for the first time around $x=0.5$. Thus, the composition $\mathrm{CoV}_{1.5} \mathrm{Fe}_{0.5} \mathrm{O}_{4}$ appears to be an optimal compromise between the high electric conductivity originating from the (normal) vanadates and the supposedly favorable inversion effect with more cobalt cations on $\mathrm{O}_{\mathrm{h}}$ sites originating from the (inverse) ferrites.

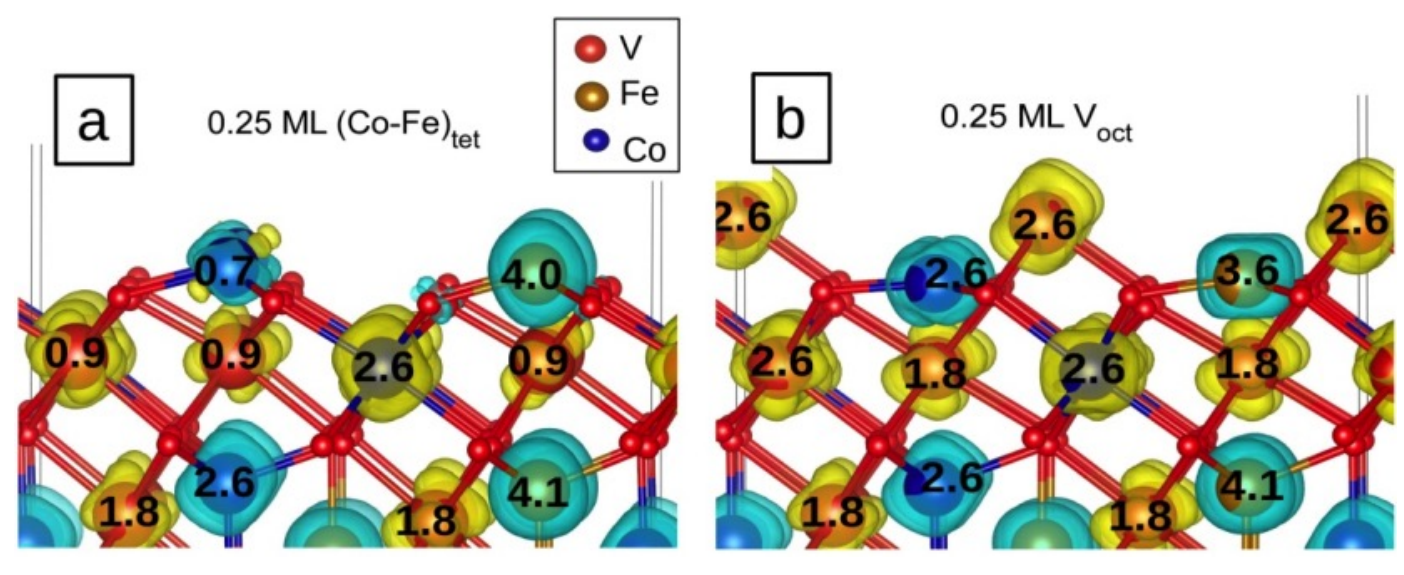

Figure 7. Spin density and magnetic moments of the (111) surface of $\mathrm{CoV}_{1.5} \mathrm{Fe}_{0.5} \mathrm{O}_{4}$ for the 0.25 $\mathrm{ML}(\mathrm{Co}-\mathrm{Fe})_{\text {tet }}$ and $0.25 \mathrm{ML} \mathrm{V}_{\text {oct }}$ terminations, respectively, indicating variation of oxidation states of the surface cations with respect to the bulk.

The magnetic moments of $\mathrm{V}^{3+}$ ions aligned along the easy axis are reduced for $\mathrm{CoV}_{1.5} \mathrm{Fe}_{0.5} \mathrm{O}_{4}$ as compared to $\mathrm{CoV}_{2} \mathrm{O}_{4}$ (maximum value $0.25 \mu_{\mathrm{B}}$ ). However, some $\mathrm{Co}^{2+}$ ions at octahedral sites have a contribution along the easy axes of $0.2 \mu_{\mathrm{B}}$. The most stable configuration in $\mathrm{CoVFeO}_{4}(x=$ 1.0) is also a half inverse spinel (the inverse spinel being $30 \mathrm{meV} / \mathrm{atom}$ higher in energy) and the 
magnetic moments of $\mathrm{V}^{3+}$ ions are aligned along the hard axis while some $\mathrm{Co}^{2+}$ ions show a slight rotation off the hard axis. For $\mathrm{CoV}_{0.5} \mathrm{Fe}_{1.5} \mathrm{O}_{4}$, the inverse structure with an inversion parameter of $\lambda=0.5$ is stabilized and the most stable ion configuration is a layered structure along the [010] direction where spins of $\mathrm{V}^{3+}$ are rotated along the easy axes. The prediction of a preferred noncollinear configuration for low iron content is in agreement with indications for considerably stronger spin canting and reduced high-field magnetization for $\mathrm{x}=0.25$ and $\mathrm{x}=0.5$ observed via Mössbauer spectroscopy and magnetometry experiments as illustrated in the supplementary (Figure S10, S11). Finally the inverse spinel structure is stable in $\mathrm{CoFe}_{2} \mathrm{O}_{4}$ which agrees well with previous work. ${ }^{28,53}$ In summary, we observe that the bulk inversion parameter $(\lambda)$ increases with the Fe content with the coordination geometries at the surface. Moreover, the spin-orbit coupling is quenched with increasing Fe concentrations.

According to the bulk calculations, the oxidation states of $\mathrm{V}^{3+}, \mathrm{Fe}^{3+}$ and $\mathrm{Co}^{2+}$ persist for the different $\mathrm{Fe}$ contents in $\mathrm{CoV}_{2-\mathrm{x}} \mathrm{Fe}_{\mathrm{x}} \mathrm{O}_{4}$. DFT+ $U$ calculations are performed for the $\mathrm{CoV}_{1.5} \mathrm{Fe}_{0.5} \mathrm{O}_{4}$ (111) surface for two terminations with a $0.25 \mathrm{ML}(\mathrm{Co}-\mathrm{Fe})_{\text {tet }}$ and a $0.25 \mathrm{ML} \mathrm{V}_{\text {oct }}$ layer. The (111)-surface with the above mentioned terminations is considered stable in spinel ferrites.$^{53}$ The spin densities and PDOS plotted in Figure 7 indicate that at the $0.25 \mathrm{ML}(\mathrm{Co}-\mathrm{Fe})_{\text {tet }}$ termination $\mathrm{V}$ indeed undergoes the transformation from $\mathrm{V}^{3+}\left(1.8 \mu_{\mathrm{B}}\right)$ to $\mathrm{V}^{2+}\left(2.6 \mu_{\mathrm{B}}\right)$ and $\mathrm{Fe}^{3+}\left(4.1 \mu_{\mathrm{B}}\right)$ to $\mathrm{Fe}^{2+}$ $\left(3.6 \mu_{\mathrm{B}}\right)$ from bulk to the surface which is in agreement with our experimental results. On the other hand, at the $0.25 \mathrm{ML} \mathrm{V}_{\text {oct }}$ termination we find indications for $\mathrm{V}^{4+}\left(0.9 \mu_{\mathrm{B}}\right)$ and $\mathrm{Co}^{2+}$ (in the low-spin state, $0.7 \mu_{\mathrm{B}}$ ), respectively.

\subsection{Bifunctionality and Stability}


Figure 8 shows the OER and ORR activity of $\mathrm{CoV}_{1.5} \mathrm{Fe}_{0.5} \mathrm{O}_{4}$ in $1 \mathrm{M} \mathrm{KOH}$ solution with a potential difference of $\Delta \mathrm{E}=0.83 \mathrm{~V}$. Notably, the difference between the potential difference of ORR and OER current is an important parameter for an overall oxygen electrode. It was evaluated at current densities of $-1 \mathrm{~mA} \mathrm{~cm}^{-2}$ for ORR and $10 \mathrm{mAcm}^{-2}$ for OER. $\mathrm{CoV}_{1.5} \mathrm{Fe}_{0.5} \mathrm{O}_{4}$ exhibit small $\Delta \mathrm{E}$ with a value of $0.83 \mathrm{~V}$ compared to pure $\mathrm{CoV}_{2} \mathrm{O}_{4}(1.01 \mathrm{~V}), \mathrm{CoFe}_{2} \mathrm{O}_{4}(1.13 \mathrm{~V})$ and very similar to $\mathrm{Pt} / \mathrm{C}(0.81 \mathrm{~V})$, demonstrating that $\mathrm{CoV}_{1.5} \mathrm{Fe}_{0.5} \mathrm{O}_{4}$ is a very promising catalyst for oxygen electrocatalysis. Supporting this material on conductive carbon might offer even more room for optimization. Stability is one of the key factors in evaluating catalyst performance. The stability of best catalyst, $\mathrm{CoV}_{1.5} \mathrm{Fe}_{0.5} \mathrm{O}_{4}$ during OER and ORR were conducted at $10 \mathrm{~mA} \mathrm{~cm}$ and-1 $\mathrm{mA} \mathrm{cm}^{-2}$ with chronoamperometric measurements, which shows little changes were observed (Figure 8B). The present study underpins the importance of the substitution effect in electrocatalytic applications for designing mixed oxide electrode materials towards water splitting.
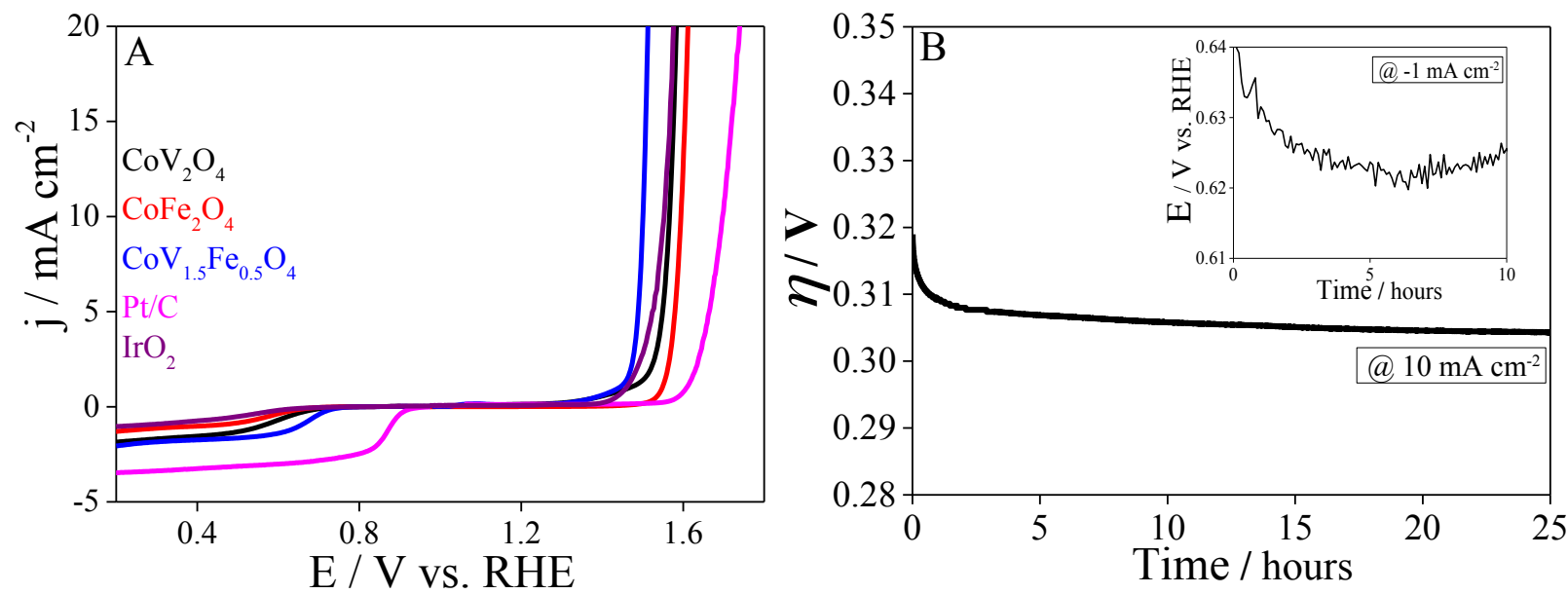

Figure 8. A) OER and ORR activity of different catalysts in $1 \mathrm{M} \mathrm{KOH}$ solution. B) chronoamperometric measurements recorded at $10 \mathrm{~mA} \mathrm{~cm}{ }^{-2}$ for OER and $-1 \mathrm{~mA} \mathrm{~cm}{ }^{-2}$ for ORR (Inset) of $\mathrm{CoV}_{1.5} \mathrm{Fe}_{0.5} \mathrm{O}_{4}$. 


\section{Conclusion}

In summary, a facile synthetic approach for nanocrystalline and phase-pure $\mathrm{CoV}_{2-\mathrm{x}} \mathrm{Fe}_{\mathrm{x}} \mathrm{O}_{4}$ with defined chemical composition and defined particle sizes in the low nm range was developed and the effect of a varying chemical composition in these spinel-type electrocatalysts was investigated. The catalytic activity was explored in the oxygen evolution (OER) and oxygen reduction reactions (ORR) and was found to be strongly influenced by the V/Fe ratio. The improved electrocatalytic activity of $\mathrm{CoV}_{2-\mathrm{x}} \mathrm{Fe}_{\mathrm{x}} \mathrm{O}_{4}$ over pure spinel-type $\mathrm{CoV}_{2} \mathrm{O}_{4}$ and $\mathrm{CoFe}_{2} \mathrm{O}_{4}$ suggests a synergetic effect of all three metal cations. A possible explanation is the high accessibility of $\mathrm{Co}^{2+} / \mathrm{Co}^{3+}$ sites at the surface as indicated by an internal redox couple $\mathrm{Co} / \mathrm{V}$ and/or a higher degree of structural inversion for the ternary oxides leading to more cobalt cations in octahedral sites. Indeed, $\mathrm{DFT}+U+\mathrm{SOC}$ calculations on cation ordering show a tendency to stabilize the inverse structure with increasing Fe concentration in $\mathrm{CoV}_{2-\mathrm{x}} \mathrm{Fe}_{\mathrm{x}} \mathrm{O}_{4}$. This effect is starts to dominate at compositions around $x=0.5$. Moreover, the effect of SOC is particularly important for low Fe concentrations but is quenched with increasing Fe content. The theoretical results also show that the variation of oxidation states are related to the surface region where we find transformation of $\mathrm{V}^{3+} \quad \mathrm{V}^{2+} \cdot \mathrm{CoV}_{1.5} \mathrm{Fe}_{0.5} \mathrm{O}_{4}$ nanoparticles are very promising for an active and stable electrocatalyst for both OER and ORR.

\section{Experimental Section}

\section{Materials}

Metal acetylacetonates $\mathrm{Co}(\mathrm{acac})_{2}, \mathrm{~V}(\mathrm{acac})_{3}$ and $\mathrm{Fe}(\mathrm{acac})_{3}$ were purchased from Sigma-Aldrich and used without further purification. Potassium hydroxide and oleylamine were obtained from 
Acros organics and degassed prior to use. Commercial $\mathrm{IrO}_{2}$ and $\mathrm{Pt} / \mathrm{C}$ were received from SigmaAldrich and used as benchmark electrocatalysts.

Synthesis of $\mathrm{CoV}_{2-x} \mathrm{Fe}_{x} \mathrm{O}_{4}$ nanoparticles

In a typical reaction, a mixture of $\mathrm{M}(\mathrm{acac})_{3}$ and $\mathrm{Co}(\mathrm{acac})_{2}(2 \mathrm{mmol}$ in total $)$ were suspended in $15 \mathrm{~mL}$ of oleylamine. The mixtures were first heated to $100{ }^{\circ} \mathrm{C}$ for $10 \mathrm{~min}$ to remove low boiling solvents resulting in a clear red solution. Then the temperature was raised to $250{ }^{\circ} \mathrm{C}$ and kept at this temperature for $60 \mathrm{~min}$. After the solution was cooled to ambient temperature, the nanoparticles were precipitated by adding $10 \mathrm{~mL}$ of ethanol. The precipitate was isolated by centrifugation, purified by repeated washing (2-3 times) with ethanol and dried in vacuum. Substituted spinel-type oxides were prepared simply by heating stoichiometric mixtures of the three different metal acetylacetonate complexes at $250^{\circ} \mathrm{C}$ for $1 \mathrm{~h}$.

\section{Structural Characterization}

Powder X-ray diffraction (XRD) patterns of nanoparticles were recorded at ambient temperature $\left(25 \pm 2{ }^{\circ} \mathrm{C}\right)$ using a Bruker D8 Advance powder diffractometer in Bragg-Brentano mode with $\mathrm{Cu}$ $\mathrm{K} \alpha$ radiation $(\lambda=1.5418 \AA, 40 \mathrm{kV}$ and $40 \mathrm{~mA})$. The powder samples were investigated in the range of 5 to $90^{\circ} 2 \theta$ with a step size of $0.01^{\circ}$ and a counting time of $0.3 \mathrm{~s}$. The size and morphology of the nanostructures were characterized by using a JEOL JEM-ARM200 F transmission electron microscope. Energy-dispersive X-ray spectroscopy (EDS) studies were carried out on a scanning electron microscope (Jeol JSM 6510) equipped with an energydispersive X-ray spectroscopy (EDX) device (Bruker Quantax 400). X-ray photo electron spectroscopy (XPS) was recorded using Versaprobe II $^{\mathrm{TM}}$ by ULVAC-Phi with a small minimal beam size of $<10 \mu \mathrm{m}$ having spectral resolution of $0.5 \mathrm{eV}$. 


\section{Magnetic Characterization}

Mössbauer spectra at $4.3 \mathrm{~K}$ have been recorded in transmission geometry in constant acceleration mode. The experiments were performed using a 1-He bath cryostat containing a superconducting magnet in split-coil geometry providing the applied magnetic field of 5T along the g-ray propagation direction. Field dependent magnetization curves were measured up to a maximum field of 9T utilizing the vibrating sample magnetometer option of a PPMS DynaCool (Quantum Design).

\section{Electrochemical Characterization}

All electrochemical measurements were performed in a conventional three-electrode cell using an Autolab potentiostat/galvanostat (PGSTAT12, Eco Chemie, Utrecht, The Netherlands) coupled to a Metrohm RDE rotator. The working electrode of disc shaped glassy carbon of geometric area $0.126 \mathrm{~cm}^{2}$ modified with the catalysts, $\mathrm{Ag} / \mathrm{AgCl} / 3 \mathrm{M} \mathrm{KCl}$ as the reference electrode and a platinum foil as counter electrode. The purity of the $\mathrm{KOH}$ electrolyte was $99.9 \%$. The activities were also tested in commercial $1 \mathrm{M} \mathrm{KOH}$ solution (Sigma Aldrich) with no impurities and similar OER activities were found. The measured potentials were converted to the

reversible hydrogen electrode (RHE) scale using the following equation $\mathrm{E}_{\mathrm{RHE}}=\mathrm{E}_{\mathrm{Ag} / \mathrm{AgCl}}+0.210 \mathrm{~V}$ $+0.059 \mathrm{pH}$. For electrochemical measurements the catalyst ink was prepared by dispersing 5.0 $\mathrm{mg} / \mathrm{mL}$ of the catalyst and $5 \mu \mathrm{L}$ of nafion in ethanol water mixture (1:1) and ultrasonicated for $30 \min$. $5.0 \mu \mathrm{L}$ of the catalyst suspension was drop coated onto the polished glassy carbon electrode and dried in air at room temperature. The modified electrodes were subjected to continuous potential cycling until reproducible voltammograms were obtained before catalytic measurements. Electrochemical impedance spectroscopy was then recorded in the frequency 
range from $50 \mathrm{kHz}$ to $1 \mathrm{~Hz}$ at the corresponding open circuit potential of the electrode, using an AC perturbation of $10 \mathrm{mV}$. The resistance of the solution was determined from the resulting Nyquist plot, and the later used for ohmic drop correction according to the relation, $\mathrm{E}_{\mathrm{c}}=\mathrm{E}_{\mathrm{m}}-\mathrm{iR}_{\mathrm{s}}$, where $\mathrm{E}_{\mathrm{c}}$ is the corrected potential and $\mathrm{E}_{\mathrm{m}}$ is the applied potential. All reported current densities were calculated using the geometric surface area of the electrode.

The number of electrons involved in the reduction process was calculated by the KouteckýLevich (K-L) equation given below.

$$
\begin{aligned}
& 1 / j=1 / j_{\mathrm{L}}+1 / j_{\mathrm{K}}=1 / B \omega^{1 / 2}+1 / j_{\mathrm{K}} \\
& B=0.62 n F C_{0}\left(D_{0}\right)^{2 / 3} v^{-1 / 6} \\
& j_{K}=n F k \mathrm{C}_{0}
\end{aligned}
$$

Here, $j$ is the measured current density, $j_{\mathrm{K}}$ and $j_{\mathrm{L}}$ are the kinetic and diffusion-limiting current densities, $\omega$ is the angular frequency of the RDE in radians per second, $n$ is the number of electrons involved in the reaction, $\mathrm{F}$ is Faraday's constant $\left(96485 \mathrm{C} \mathrm{mol}^{-1}\right), \mathrm{D}_{0}$ is the diffusion coefficient of $\mathrm{O}_{2}$ in the electrolyte $\left(1.93 \times 10^{-5} \mathrm{~cm}^{2} \mathrm{~s}^{-1}\right)$, vis the kinematic viscosity of the electrolyte $\left(1.01 \times 10^{-2} \mathrm{~cm}^{2} \mathrm{~s}^{-1}\right), \mathrm{C}_{0}$ is the concentration of $\mathrm{O}_{2}$ in the electrolyte $\left(1.26 \times 10^{-6} \mathrm{~mol}\right.$ $\mathrm{cm}^{-3}$ ) and $k$ is the electron transfer rate constant.

\section{Computational details}

The density-functional theory (DFT) calculations were performed by using of the VASP code within the projected-augmented waves (PAW) method. ${ }^{50,51}$ The spin-orbit coupling and noncollinear magnetism are implemented within the PAW framework. ${ }^{51}$ The structures were fully 
optimized within the generalized-gradient approximation $(\mathrm{GGA})^{54}$ for the exchange-correlation functional together with an on-site Hubbard $U$ term at the transition metal cation sites. ${ }^{55}$ Then the SOC included to the calculations. Overall, more than 100 configurations were investigated to identify the most stable configurations for different $\mathrm{V}_{2-\mathrm{x}} \mathrm{Fe}_{\mathrm{x}}$ concentration. In line with previous theoretical investigations we used the on-site Hubbard- $U$ parameter of $U_{\mathrm{Fe}}=4.3, U_{\mathrm{Co}}=4.0, U_{\mathrm{V}}$ $=3.4 \mathrm{eV}$ and a Monkhorst-Pack grid of $6 \times 6 \times 6 \mathrm{k}$-points for all calculations. The cutoff energy of $500 \mathrm{eV}$ and forces of $10^{-6} \mathrm{eV} / \AA$ were used for ionic relaxations.

The complex behavior of spinel vanadates originates from several competing interactions among spin, orbital and lattice degrees of freedom. ${ }^{56,57}$ The exchange interactions between $\mathrm{V}$ and $\mathrm{Co} / \mathrm{Fe}$ results in a complicated non-collinear magnetic order at low temperatures ${ }^{58,59}$ Recalling that $\mathrm{CoV}_{2} \mathrm{O}_{4}$ and $\mathrm{CoFe}_{2} \mathrm{O}_{4}$ are considered to be normal ${ }^{52}$ and inverse ${ }^{53}$ spinels, the type of cation ordering for different concentrations of $\mathrm{V}$ and Fe cations remains unknown but can influence the inversion parameter and spin-orbit interaction of these compounds. Moreover, substitution of iron with vanadium can modify the magnetic frustration and orbital pattern in $\mathrm{CoV}_{2-\mathrm{x}} \mathrm{Fe}_{\mathrm{x}} \mathrm{O}_{4}$. In particular, the relative formation energies of different cation ordering of $\mathrm{CoV}_{2-\mathrm{x}} \mathrm{Fe}_{\mathrm{x}} \mathrm{O}_{4}(\mathrm{x}=0.0,0.5$, $1.0,1.5,2.0)$ for inversion parameters of $\lambda=0.0,0.5,1.0$ were calculated. In a normal spinel $(\lambda=$ 0.0), all tetrahedral sites are occupied by Co and octahedral sites are distributed between Fe and V. At $\lambda=0.5$, half of the Co ions occupy the tetrahedral and the other half octahedral sites. Correspondingly, $\mathrm{Fe} / \mathrm{V}$ occupies half of the tetrahedral and $3 / 4$ of the octahedral sites. Finally, for the inverse spinel, tetrahedral sites are occupied only by V and Fe and octahedral sites can be occupied by all three transition metal ions. The relative formation energies can be calculated from the total energy of different structures with respect to the energy of the end members $\mathrm{CoV}_{2} \mathrm{O}_{4}$ andCoFe $\mathrm{O}_{4}$ : 


$$
\Delta E_{f}=E_{\lambda}^{\mathrm{CoV}_{2-x} \mathrm{Fe}_{x} \mathrm{O}_{4}}-\left(\frac{x}{2}\right) E_{\lambda=1}^{\mathrm{CoFe}_{2} \mathrm{O}_{4}}-\left[1-\left(\frac{x}{2}\right)\right] E_{\lambda=1}^{\mathrm{CoV}_{2} \mathrm{O}_{4}}
$$

Where $\mathrm{x}$ is the relative concentration of $\mathrm{Fe}$ and $\lambda$ is the inversion parameter. The total energies of $\mathrm{CoVO}_{4}$ and $\mathrm{CoFeO}_{4}$ for the inverse structures are chosen as references.

\section{ASSOCIATED CONTENT}

Supporting Information. Additional characterization data includes TEM, XPS, Mossbauer electrochemical characterization and DFT calculations.

\section{AUTHOR INFORMATION}

\section{Corresponding Author}

stephan.schulz@uni-due.de,malte.behrens@uni-due.de.

\section{ACKNOWLEDGMENT}

This work was supported by the State of North Rhine-Westphalia within the Project HOXIKAT of the Program "Starke Forschung Chemie.NRW" (FKZ 005-1703-0032), by the Mercator Research Center Ruhr (MERCUR ST-2017-0001), and by the Deutsche Forschungsgemeinschaft (DFG) within the SPP 1613 (BE4767/2-2), SPP 1681 (WE2623/7-2) and FOR 1509 (WE2623/13). The DFG core facility "Interdisciplinary Center for Analytics on the Nanoscale (ICAN)" at the University of Duisburg-Essen, Prof. M. Epple (XRD), Prof. S. Barcikowski (disc centrifuge) of the University Duisburg-Essen are gratefully acknowledged for allocating access to their characterization facilities. We thank Dr. Ulrich Hagemann (ICAN) for fruitful discussions. 


\section{SUPPORTING INFORMATION}

Additional TEM images, electrochemical measurements, XP spectra, details of the computational results and Mössbauer spectroscopy

\section{REFERENCES}

1) Yang, G. ; Choi,W. ; Xiong,P. ; Yu,C.Energy Environ. Sci.2015, 8, 1799-1807.

2) Dresp,S.; Luo,F.; Schmack,R.; Kühl,S.; Gliech,M.;Strasser,P.Energy Environ. Sci.2016, 9, 2020-2024.

3) Fu,G.; Cui,Z.; Chen,Y.; Li,Y.; Tang,Y.; Goodenough,J. B.Adv. Energy. Mater.2016, 1601172.

4) Dou,S.; Tao,L.; Huo,J.; Wang,S.; Dai,L.Energy Environ. Sci.2016, 9, 1320-1326.

5) Liu,Q.; Wang,Y.; Dai,L.; Yao,J.Adv. Mater. 2016, 28, 3000-3006.

6) McCrory,C. C. L.; Jung,S.; Peters,J. C.; Jaramillo,T. F.J. Am. Chem. Soc.2013, 135, $16977-16987$.

7) Li,C.; Han,X.; Cheng,F.; Hu,Y.; Chen,C.; Chen,J.Nat. Commun. 2015, 6, 7345.

8) Lukowski,M. A.; Daniel,A. S.; Meng,F.; Forticaux,A.; Li,L. Jin,S.J. Am. Chem. Soc.2013, 135, 10274-10277.

9) Hou,Y.; Wen,Z.; Cui,S.; Ci,S.; Mao,S.; Chen,J. Adv. Funct. Mater.2015, 25, 871-882.

10) Qian,L.; Lu,Z.; Xu,T.; Wu,X.; Tian,Y.; Li,Y.; Huo,Z.; Sun,X.; Duan,X.Adv. Energy Mater. 2015, 1500245.

11) Cheng,F.; Shen,J.; Peng,B.; Pan,Y.; Tao,Z.; Chen,J.Nat. Chem.2011, 3, 79-84.

12) Gao,T.; Jin,Z.; Liao,M.; Xiao,J.; Yuana,H.; Xiao,D.J. Mater. Chem. A2015, 3, 1776317770. 
13) Fan,K.; Chen,H.; Ji,Y.; Huang,H.; Claesson,P. M.; Daniel,Q.; Philippe,B.; Rensmo,H.; Li,F.; Luo,Y.; Sun,L.Nat.Commun.2016, 7, 11981.

14) Fominykh,K.; Chernev,P.; Zaharieva,I.; Sicklinger,J.; Stefanic,G.; Doblinger,M.; Müller,A.; Pokharel,A.; Scheu,C.; Bein,T.; Fattakhova-Rohlfing,D. ACS Nano2015, 9, $5180-5188$

15) Smith,R. D.; Prevot,M. S.; Fagan,R. D.; Zhang,Z.; Sedach,P. A.; Siu,M. K. J.; Trudel,S.; Berlinguette,C. P.Science 2013, 340, 60-63.

16) Schwanke,C.; Stein,H. S.; Xi,L.; Sliozberg,K.; Schuhmann,W.; Ludwig,A.; Lange,K. M.Sci.Rep.2017, 7, 44192.

17) Zou,S.; Burke,M. S.; Kast,M. G.; Fan,J.; Danilovic,N.; Boettcher,S. W.Chem . Mater.2015, 27, 8011-8020.

18) Liang,Y.; Li,Y. G.; Wang,H. L.; Zhou,J. G.; Wang,J.; Regier,T.; Dai,H. J.Nat. Mater.2011, 10, 780-786.

19) Morales-Guio,C. G.; Liardet,L.; Hu,X.J. Am. Chem. Soc.2016, 138, 8946-8957.

20) Zhang,B.;Zheng,X.; Voznyy,O.; Comin,R.; Bajdich,M.; Garcia-Melchor,M.; Han,L.; Xu,J.; Liu,M.; Zheng,L.; Garcia de Arquer,F. P.; Dinh,C. T.; Fan,F.; Yuan,M.; Yassitepe,E.; Chen,N.; Regier,T.; Liu,P.; Li,Y.; De Luna,P.; Jan-mohamed,A.; Xin,H. L.; Yang,H.; Vojvodic,A.; Sargent,E. H.Science 2016, 352, 333-337.

21) Risch,M.; Stoerzinger,K. A.; Maruyama,S.; Hong,W. T.; Takeuchi,I.; Shao-Horn,Y.J. Am. Chem. Soc.2014, 136, 5229-5232.

22) Jung, J-I.; Risch, M.; Park, S.; Kim, M. G.; Nam, G.;Jeong,H-Y.; Shao-Horn,Y.; Cho,J. Energy Environ. Sci.2016, 9, 176-183. 
23) Fan, K.;Ji,Y. F.; Zou,H. Y.; Zhang,J. F.; Zhu,B. C.; Chen,H.; Daniel,Q.; Luo,Y.; Yu,J. G.; Sun,L. C.Angew. Chem. Int. Ed. 2017, 56, 3289-3293; Angew. Chem. 2017, 129, 3337-3341.

24) Zhu,H.; Zhang,S.; Huang,Y.-X.; Wu,L.; Sun,S.Nano. Lett.2013, 13, 2947-2951.

25) Wu,G.; Wang,J.; Ding,W.; Nie,Y.; Li,L.; Qi,X.; Chen,S.; Wie,Z.Angew. Chem. Int. Ed. 2016, 55, 1340-1344; Angew. Chem. 2016, 128, 1362-1366.

26) Bao,J.; Zhang,X.; Fan,B.; Zhang,J.; Zhou,M.; Yang,W.; Hu,X.; Wang,H.; Pan,B.; Xie,Y.Angew. Chem. Int. Ed.2015, 54, 7399-7404; Angew. Chem. 2015, 127, 7507-7512.

27) Menezes,P. W.; Indra,A.; Bergmann,A.; Chernev,P.; Walter,C.; Dau,H.; Strasser,P.; Driess,M.J. Mater. Chem. A2016, 4, 10014-10022.

28) Chakrapani, K.; Bendt,G.; Hajiyani,H.; Schwarzrock,I.; Lunkenbein,T.; Salamon,S.; Landers,J.; $\quad$ Wende,H.; $\quad$ Schlögl,R.; $\quad$ Pentcheva,R.; $\quad$ Behrens,M.; Schulz,S.ChemCatChem2017, 9, 2988-2995.

29) Koborinai,R.; Dissanayake,S. E.; Reehuis,M.; Matsuda,M.; Kajita,T.; Kuwahara,H.; Lee,S.-H.; Katsufuji,T.Phys. Rev. Lett.2016, 116, 037201.

30) Kismarahardja, A.; Brooks,J. S.; Kiswandhi,A.; Matsubayashi,K.; Yamanaka,R.; Uwatoko,Y.; Whalen,J.; Siegrist,T.; Zhou,H. D.Phys. Rev. Lett.2011, 106, 056602.

31)Zhang,Y.; Liu,Y.; Chen,J.; Guo,Q.; Wang,T.; Pang,H.Sci.Rep.2014, 4, 5687.

32) Xing, M.; Kong, L.-B.; Liu, M.-C.; Liu,L.-Y.; Kang,L.; Luo, Y-C.J. Mater. Chem. A2014, 2, 18435-18443.

33) Yang,G.; Cui,H.; Yang,G. W.; Wang,C. X.ACS Nano 2014, 8, 4474-4487.

34) Brik, M. G.; Suchocki, A.; Kaminska, A. Inorg . Chem.2014, 53, 5088-5099. 
35) Silversmit,G.; Depla,D.; Poelman,H.; Marin,G. B.; De Gryse,R.J. Electron Spectrosc.Relat. Phenom.2004, 135, 167-175.

36) Biesinger, M. C.; Lau,L.; Gerson,A. R.; Smart,R. S. C.Appl. Surf. Sci.2010, 257, 887898.

37) Nohair,M.; Perriat,P.; Domenichini,B.; Gillot,B.Thermochim. Acta1994, 244,223- 234.

38) Righter,K.; Sutton,S. R.; Newville,M.; Le,L.; Schwandt,C. S.; Uchida,H.; Lavina,B.; Downs,R. T.American Mineralogist 2006, 91, 1643-1656.

39) Grosvenor,A. P.; Kobe,B. A.;McIntyre,N.S. Surf. Sci. 2004, 565, 151-162.

40) Brabers,V. A. M.; van Setten,F.J. Phys. D: Appl. Phys.1983, 16, L169-L172.

41) Oku,M.; Hirokawa,K.J. Electron Spectrosc. Relat. Phenom.1976, 8, 475-481.

42) Diodati,S.; Pandolfo,L.; Caneschi,A.; Gialanella,S.; Gross,S.Nano Research2014, 7, 1027-1042.

43) Vaz, C. A. F.; Prabhakaran,D.;Altman,E. I.; Henrich,V. E.;Phys. Rev. B. Condens. Matter Mater. Phys.2009, 80, 155457.

44) Xie,J.; Zhang,H.; Li,S.; Wang,R.; Sun,X.; Zhou,M.; Zhou,J.; Wen,X.; Xie,Y.Adv . Mater.2013, 25, 5807-5813.

45) Lukowski,M. A.; Daniel, A. S.; Meng,F.; Forticaux,A.; Li,L. Jin,S.J. Am. Chem. Soc.2013, 135, 10274-10277.

46) Liu,S.; Bian,W.; Yang,Z.; Tian,J.; Jin,C.; Shen,M.; Zhou,Z.; Yang,R. J. Mater. Chem. A2014, 2, 18012-18017.

47) Chakrapani,K.; Sampath,S.Phys. Chem. Chem. Phys.2014, 16, 16815-16823.

48) Liang,H. W.; Cao,X.; Zhou,F.; Cui,C. H.; Zhang,W. J.; Yu,S. H.Adv. Mater. 2011, 23, 1467-1471. 
49) Koenigsmann,C.; Zhou,W. P.; Adzic,R. R.; Sutter,E.; Wong,S. S.Nano Lett. 2010, 10, 2806-2811.

50) Kresse, G.; Furthmüller, J.Phys. Rev. B1996, 54, 11169-11186.

51) Steiner,S.; Khmelevskyi,S.; Marsman,M.; Kresse,G.Phys. Rev. B2016, 93, 224425.

52) Fritsch,D.; Ederer,C.Appl. Phys. Lett. 2011, 99, 081916.

53) Kumar,P. V.; Short,M. P.; Yip,S.; Yildiz,B.; Grossman,J. C.J. Phys. Chem. C2013, 117, $5678-5683$.

54) Perdew „J. P.; Burke,K.; Ernzerhof,M.Phys. Rev. Lett. 1996, 77, 3865-3868.

55) Dudarev,S. L.; Botton,G. A.; Savrasov ,S. Y.; Humphreys,C. J.; Sutton,A. P.Phys. Rev . B1998, 57, 1505-1509.

56) Radaelli, P. G.New J. Phys. 2005, 7, 53.

57) Tsunetsugu,H.; Motome, Y.Phys. Rev. B2003, 68, 060405.

58) Wheeler,E. M.; Lake,B.; Nazmul Islam,A. T. M.; Reehuis,M.; Steffens,P.; Guidi,T.; Hill,A. H.Phys. Rev. B 2010, 82, 140406.

59) Kismarahardja,A.; Brooks,J. S.; Kiswandhi,A.; Matsubayashi,K.; Yamanaka,R.; Uwatoko,Y.; Whalen,J.; Siegrist,T.; Zhou,H. D.Phys. Rev. Lett. 2011, 106, 056602.

\section{TOC GRAPHIC}




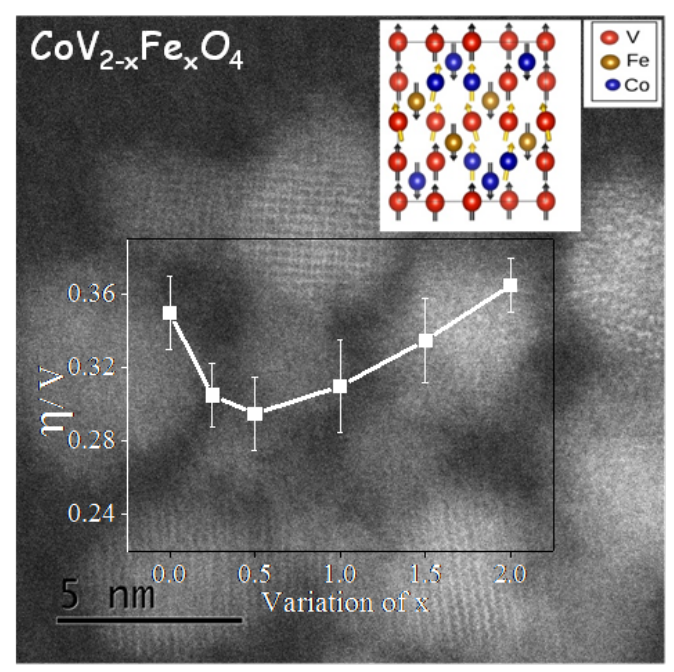


This text is made available via DuEPublico, the institutional repository of the University of Duisburg-Essen. This version may eventually differ from another version distributed by a commercial publisher.

DOI: $\quad 10.1021 /$ acscatal.7b03529

URN: urn:nbn:de:hbz:464-20201215-142647-0

This document is the Accepted Manuscript version of a Published Work that appeared in final form in: ACS Catal. 2018, 8, 2, 1259-1267, copyright (C) American Chemical Society after peer review and technical editing by the publisher. To access the final edited and published work see: https://doi.org/10.1021/acscatal.7b03529

All rights reserved. 